Juliusz Domański

\title{
DE PHILIPPI CALLIMACHI IN VIII BEATITUDINES HOMILIA OBSERVATIONES
}

\section{SŁOWA KLUCZOWE}

Filippo Buonaccorsi (Callimachus Experiens) jako homileta, osiem błogosławieństw ewangelicznych, binarny układ błogosławieństw w homilii Kallimacha

Philippus ille Buonaccorsius, qui sibi Callimachi poetae Graeci indidit nomen, quidnam sive de religione in universum sive de fide Christiana senserit, haud semel iam est a viris doctis disputatum. Ne vetustiora leviorisque momenti, liceat saltem ea in memoriam revocare, quae vir doctissimus Caesar Vasoli nuper protulit in libro e plurium commentationibus conflato atque de Philippo Callimacho arti poeticae colendae eodemque publicis negotiis obeundis dedito imprimis tractante. Sicut alii fere, qui iam eandem quaestionem discutiebant, id potissimum egit etiam peculiaris illius commentationis Callimacheas de religione opiniones egregie illustrantis auctor, ut quaenam ratio mutua inter religiosam fidem et rationem philosophicam intercedere Callimacho visa esset, ostenderet explicaretque. Asserit enim ea re insignem esse omnem quaestionum de philosophia a Callimacho institutarum disceptationem, quod diligentissime atque strenuissime separantur ab illo philosophia et religio, ratio et fides, rerum natura et sacra religionis mysteria nihilque in ipsa tractandi disputandique ratione alteram rem cum altera commune habere posse ipsi videri. Accedit quod praecipuum quoddam religionis cuiuscumque pretium inde potissimum aestimandum Callimachus

Juliusz Domański - prof. emerytowany, Instytut Filozofii i Socjologii, Polska Akademia Nauk, ul. Nowy Świat 72, 00-330 Warszawa; Instytut Filologii Klasycznej, Uniwersytet Warszawski, ul. Krakowskie Przedmieście 1, 05-077 Warszawa; e-mail: juldom@poczta.onet.pl 
putat, si societatem humanam firmo quodam stabilique religio coniungat vinculo in regendisque civitatibus efficax quoddam praestet adiutorium. Et haec quidem iure suo a viro doctissimo asseruntur, sic enim res ipsa sese habet cum in Callimachea Gregorii Sanocei vita (ubi certe propria etiam sua, non autem sola Gregorii in medium Callimachus profert placita), tum vero in epistulis ad Marsilium Ficinum Ioannemque Picum Mirandulanum datis. Ubique certe Callimachea disceptatio "quid demum aut velit aut ferat natura rerum exquirit, non religionum mysteria”, ut ipse in epistula ad Picum scripta fatetur. At neque in Caesaris Vasoli recentissima atque peculiari neque in vetustioribus alioque spectantibus aliorum commentationibus praeter philosophica ilia iam nominata scripta (quibus adicitur interdum etiam Callimachea Praefatio in Somniarium Leonis Tusci) aliud umquam in quaestionem vocatur Callimachi opusculum, quo quidem ille non solitam philosophi, sed insuetam sibi theologi iniit viam, homiliam dico super evangelium de octo beatitudinibus inscriptam et peculiari epistula anonymo cuidam regni Poloniae vicecancellario dedicatam.

Quod opusculum - mirum sane in modum a Callimacheorum scriptorum indagatoribus neglectum, ipsa enim eius typis excusa editio vix ante viginti hos annos primum lucem vidit, sed ne typis quidem excusa eorum in sese convertit oculos - vel propterea dignum fuit in quod attentius diligentiusque inquireretur, quod religionis Christianae quaestiones, a quibus tractandis alibi omnino abhorret, libens hic Callimachus suscipit explicandas. Quae quaestiones etiamsi ad moralem potissimum pertinent Christianae doctrinae partem, nihilominus tamen in ipso mysteriorum Christianorum versantur meditullio, quod autem gravioris etiam videtur esse momenti, non solis ex religione Christiana petitis, verum philosophicis etiam - res nimirum, quam apud eiusmodi auctorem vix exspectares - explicantur rationibus, quid aliud testificantes quam quod Callimachus a solita sibi alioqui methodo in hac homilia componenda omnimo discessit? Quod cum ita sit, operae pretium facturi videmur, si hanc disputandi methodum, tantopere Callimacho insuetam, vel pauculis allatis exemplis quoad fieri poterit illustremus. Sed exempla illa, quamquam perpauca, sic potissimum afferenda esse puto, ut totius Callimacheae disputationis tenor brevissime adumbretur, ne forte in solam methodum attenti, quidnam ille de rebus senserit, in quas inquirebat, nihil omnino dixisse videamur.

Atque universam quidem versibus 2-10 quinti capitis Evangelii secundum Matthaeum comprehensam materiam ita Callimachus illustrandam sibi explicandamque distinxit, ut unicuique beatitudini enarrandae quasi quoddam peculiare destinaverit capitulum, ordinem tamen, quo singulae in Evangelio habentur, minime servaverit. Cum enim apud Matthaeum primum "pauperes spiritu", deinde "mites", tum "qui lugent", tum "qui esuriunt et sitiunt iustitiam", 
tum "misericordes", tum qui "mundo" sunt "corde", tum "pacifici", postremo "qui persecutionem patiuntur propter iustitiam" praedicentur beati, separatim videlicet unumquodque genus, Callimacho ordinem hunc mutanti hoc imprimis cordi videtur fuisse, ut non tam singulas atque a se invicem separatas, ut in Evangelio, sed potius binarias perpenderet beatitudines. Ait enim de Christo octo illas beatitudines apud Matthaeum annuntiante:

[...] dinumerans octo ordines agentium in vita quattuor uelut gradibus distinxit ea, quae maxime difficilia toleratu uidentur hominibus, quattuorque uirtutes illis apposuit, per quas, dum in hoc humanarum perturbationum fluctu agitamur, subleuemur a proximo, consolemur, erigamur ac ueluti manu ducamur ad uitam aeternam, quam in hodierna doctrina tam spernentibus res humanas quam his, qui illis bene utuntur, repromittit; eaque est ratio, ob quam pauperibus misericordes, humilibus innocentes, lugentibus pacificos, iustitiam agentibus iustos apposuit et tam istos quam illos beatos uocauit.

Atque virtutes quidem illas nusquam Callimachus in homilia sua nominavit aut propius definivit. At singularum beatitudinum quasi duplicem quandam esse naturam inde ab homiliae exordio significavit, cum eas, sensus ambiguitatis cuiusdam in ipso Evangelii textu haud ignarus, partim huic terrenae, partim futurae demum attribueret hominum vitae. Haec enim post verba nuperrime citata illico addit: "quae distinctio et doctrina ut efficax ad salutem et commoda, ita conformis statui et condicioni, in qua homo in ipsa creatione est constitutes". His autem verbis - sed multo etiam clarius (quod mox apparebit) quibusdam, quae infra sequuntur - innuere videtur beatos quodammodo in terrena iam societatis humanae vita esse eos, qui beati a Christo praedicantur. Ceterum, cum saepius asseveret beatitudines a Christo promissas cum eo potissimum hominis statu, in quo is initio creatus est, congruere, hic illic tamen hoc etiam in memoriam revocat, eis hominibus promissiones illas a Christo datas, qui propter peccatum originale multis affecti sunt debilitatibus atque miseriis. Quae omnia, cum Callimachi de religione placitis aliunde notis collata, digna sane videntur quae singillatim etiam hic enarrentur.

Ac primum quidem, neglecto velut omnino debilitato isto ob peccatum originale naturae humanae statu, de quo in eis etiam, quae sequuntur, vix una aut altera fit mentio, a spiritu paupertatis incipiens paupertatem ideo potissimum a Christo tantopere commendatam asserit, ne divitiis admirandis expetendisque a Dei divinorumque avocaremur contemplatione. Ei autem rei documento primum in ipsa creatione id fuisse autumat, quod Deus "nudum hominem creauit et nudum dimisit expositis passim alimentis, quibus sine ulla opera aut cura aleretur", deinde vero, "cum abusus earum rerum, quas ad arctandas necessitates 
Deus nobis induxerat, paupertatem uelut execrabilem detestandamque hominibus reddidisset", Christi ipsius tum nativitas tum vita, "quippe quod ex paupera matre in domo pauperrima nasci uoluerit et sub pauperis Ioseph disciplina educari", tum pauperrimorum item Ioannis Baptistae apostolorumque facta a Christo electio, postremum ea, quae apostolis omnibusque suis discipulis atque asseclis mandavit Christus, "ut quod pater creatione seruauerat, ipse in omni actione et uita sua imitaretur; nec minus a suis imitari placuit".

Paupertati - quam a ratione cuique homini commendari quamque duplicem esse Callimachus asserit, videlicet aut re ipsa, i.e. vera rerum inopia, consistentem aut spiritu paupertatis, i.e. sincero divitiarum contemptore, effectam, illamque paupertatem sine hac falsam quodammodo esse atque inanem, cum spiritus paupertatis vel ditissimum copiisque affluentem vere pauperem reddat - quasi ex opposita parte adiungitur a Callimacho misericordia, adiutricis cuiusdam humanam fragilitatem fulcientis gerens vicem et ita demum una cum paupertate virtutem nescio quam efficiens. "Vidit diuina sapientia", inquit, "fragilitatem humanam facile posse sub paupertatis onere deficere in cursu, antequam ad propositum praemium perueniret, atque ideo, ut esset, quod deficientem subleuaret, non solum infudit homini rationem, per quam instabilitatem rerum humanarum intelligeret ac proinde misereretur eorum, quos a fortuna destitutos uideret, quam se felicitate sua efferret, quam inconstantem momentaneamque sciret, sed etiam quandam mollitiem animis nostris infixit, per quam cogimur etiam inuiti commoueri ad calamitates cruciatusque proximi”. Cum ergo ratio unicuique seu re seu spiritu pauperi propriam, paupertatem tolerare commendet, misericordia alterius eandem paupertatem leviorem tolerabilioremque efficit, tum opibus egentem efficaciter sublevando, tum vero animo eius solatium quoddam afferendo vel saltem pauperi compatiendo. "Sciendum est", inquit deinde Callimachus, "secundum Paulum ad Galatas misericordiam esse alienae miseriae in nostro corde compassionem, quam utique, si possemus, subleuare compellimur, ex quo colligo non minus ad uoluntatem quam ad elimosinam pertinere misericordiam. Tantundem dicit misericordem ilium, qui libenter alleuiaret proximi necessitatem, si posset, quam qui alleuiat; atque unicuique tam inopi quam diuiti licet, ut sit misericors". Spiritalis itaque imprimis et interna cuiusque res est Callimacho misericordia, sicut et paupertas, secundo tamen loco etiam communi societatis humanae vitae utilitatem quandam afferens.

Ad mites deinde transiens beatos in Evangelio praedicatos, hanc quoque animi humani indolem, qua omnia adversa facillime tolerari putat quamque aptissime mansuetudinem appellares, ipso creationis actu soli homini inditam esse asserit, cui rei documento id esse autumat, quod Deus "cum cetera animalia partim pedibus, partim unguibus, alia dentibus, alia cornubus efferasset, membra 
hominis sic disposuit, ut patiendae tantummodo iniuriae uideatur accommodasse, nullo ei dato adminiculo, per quod facile inferre aut commode uim posset propulsare; menti uero tantam mansuetudinem infudit, quantam profecto non infudisset, nisi nos patientiae atque humilitati praeparasset". Quae mansuetudo cum in Veteris Testamenti libris tum vero in Evangelio tantopere a Christo et aliis rationibus et hac praecipue, quod "mites terram possidebunt", recommendata, ad eiusmodi quaestionem ponendam tribusque modis soluendam Callimachum tandem adducit:

Quare autem humilibus terram subiecerit dicendo, quod mites terram possidebunt, sic accipimus, quod ratione uincent appetitum et gubernabunt neque sensu inclinabuntur ad ea, quae mundi sunt, sed ratione illis dominabuntur: aut certe dicamus possessuros terram, sicut ceteri beati neque illud dici forte absurdum, quod cum ex terra simus, ille dici merito potest terram possidere, qui se ipsum in potestate habet et sibi in frenandis cupiditatibus, ut uult, imperat.

Inter tres hos quaestionis soluendae modos etiamsi is qui primus ponitur Christianam quadamtenus redolet q.d. eschatologiam, attamen ad duos reliquos quod attinet, potius a philosopho quodam vel Stoicae vel alterius etiam cuiusvis prosapiae rationem humanam affectus sibi efficaciter subicientem laudibus efferri diceres quam debilitatem humanam aerumnis cruciatibusque praecipua quadam Dei gratia confortandam a theologo Christiano describi. Similiter res sese habet in eis, quae de cordis puritate paulo inferius disseruntur, nisi quod in his tractandis eum sese Callimachus imprimis ostendit philosophum, cui ut alibi ita hac etiam in homilia communis societatis humanae utilitas praecipue cordi videtur esse. Sic enim eum qui mundo est corde definit: "Ille [...] est mundo corde, qui est innocens. Innocens autem non solum, qui nemini nocet, sed etiam prodest unicuique, cum potest. Non enim sufficit non nocere, nisi et prosit si potest. Haec uirtus innocentiae ut ad salutem imprimis necessaria, ita propemodum a natura infundi nobis deberet", et quidem "deberet" tum propterea, quod Deo originem nostram homines debemus, tum propter innumeras "in uita [...] debilitates, aerumnas infelicesque casus [...], ut quem metus futurae poenae continere in malo non potest, praesertim calamitatum, quas in aliis uidemus, acerbitas debet cohibere", a cordis videlicet impuritate.

Quod igitur duplicem illam beatitudinum evangelicarum attinet naturam in Callimachi interpretatione obviam, aeternam nempe futuraeque demum vitae propriam et temporalem, qua in terrestri iam vita nescio quo modo fruuntur homines, certe ulterior haec praevalet in exemplis hucusque a me allatis. Neque tamen is fuit Callimachus qui omnino oblitus sit cum caelestibus imprimis aeternisque rem sibi in Evangelio esse beatitudinibus, multo potius futurae 
demum quam praesenti hominum vitae promissis. Quod cum iam in ipsis adhuc allatis quadamtenus significatum est explanationibus, tum praecipue in eis quae sequuntur clarius etiam apparet.

Subsequitur enim primum lugentium beatitudinis explanatio, explanationi vero praemittitur luctus definitio quasi ex media Stoicorum philisophia deprompta haec: "luctus est aegritudo inhaerens animo aut dolore amissi boni aut metu imminentis in futurum mali". Nihilominus tamen post philosophicam hanc luctus definitionem illico docemur, tum propter peccatum originale, tum propter terrenam nostram originem (caelesti illi origini, de qua paulo ante fecit verba, ob duplicem hominis naturam omnino congruam), donec in terris commoramur, perpetuo nobis in luctu vivendum. Quae sententia non solum propius quam philisophici illi loci, quos nuper indicavimus, ad genuinum Christianae doctrinae accedit spiritum, verum etiam famosam illam alto medio aevo tantopere adamatam redolere videtur de miseria condicionis humanae deque contemptu mundi doctrinam, siquidem haec de humana condicione a Callimacho dicuntur: "creatio nostra ex terra est, generatio in culpa, natiuitas ad poenam, uita uero uniuersa flagitiis ac turpitudine corrupta" Atque eiusmodi quidem miseriae nec non luctus, qui miseria illa efficitur, futurae demum vitae et in Evangelio apertissime promittitur consolatio et Callimachus eam futura demum in vita hominibus adipiscendam esse variis explicat modis

Lugentibus - explicandi ordinem exsequens eum, quem sibi initio proposuit et quo singulas beatitudines binatim, ut ita dicam, illustrare animum induxit - pacificos consociat. A pacifico autem homine non solum appeti dicit internam quandam cordis tranquillitatem et quidem hac potissimum ratione appeti, quod homo eiusmodi "spretis omnibus sola, quae sursum sunt, sapit et meditatur, quae ueluti quadam electione praefert temporalibus, sed praeter illa nihil appetendum omnino mortalibus putans, quasi humana non essent, diuinis tantummodo intentus est"; immo, pacificum hominem tranquillitate illa iam hic in terra reapse frui, etenim "qui [...] nihil humanum appetit, cupiditatibus uacat, qui uacat cupiditatibus, quietus est". Quae Callimachea pacis Christianae interpretatio, quamquam tam eleganti conclusa est syllogismo, verbis, ut videtur, e philosophorum sermone depromptis formato, nihilominus tamen et Bernardi Claraevallensis corroboratur auctoritate et cum in pacem illam a Christi apostolis apud Ioannem $(14,27)$ datam tum in alios etiam Evangeliorum extenditur locos, ubicumque pax eiusmodi in interiore homine residere dicitur, internae autem pacis illius, sicut et prius veri luctus ex humanae miseriae consideratione provenientis, praecipui antistites praedicantur monachi. Hoc modo, postquam lugentium beatitudinem futurae demum et caelesti prius assignavit vitae, inductis nunc pacificis in terrena iam vita beatis aequalitatem quandam futurae et praesentis 
beatitudinis assequi videtur, simillimam ei, quam in primis duabus beatitudinibus explicandis vidimus.

Simili quadam aequalitate sive potius aequilibrio insignes videntur etiam reliquae duae beatitudines, sitientium nempe et ensurientium iustitiam nec non iustorum, in homiliae fine coniunctim illustratae. Quamquam enim "sitientium esurientiumque iustitiam quae sit societas", sibi explicandum initio proposuit abiectaque eorum opinione, qui consueverunt "sic interpretari sitientes iustitiam, quasi cupientes a Deo iustificari”, in hac quoque beatitudine explicanda, sicut in reliquis, asseverat "nihil aliud uoluisse Saluatorem nostrum, quam consolari miserum genus humanum ad ferenda patienter omnia, quae mundus dat, ut in caelis cum Deo beatitudine fruamur aeterna", nihilominus tamen mox de sitiente esurienteque iustitiam haec dicit, sitim eiusmodi atque esuritionem in terris iam beatitudine vera quodammodo rependi posse testificantia: "Cupit enim bonus quisque iustitiam, uidelicet ut, quod proprium est iustitiae, unicuique, quod suum est, reddatur, eaque cupiditate iustus dici meretur et, si iustus, sine dubio beatus". Accedit quod eorum etiam beatitudinem, qui, ut sunt Evangelii verba, "persecutionem patiuntur propter iustitiam' et quos, iustos a se appellatos, cum sitientibus esurientibusque iustitiam apte in unius eiusdemque virtutis adumbratione complexus est, cum ad effectum in terrena iam vita adduci tum ipsam iustitiae esurientium sitientiumque beatitudinem quodammodo adiuvare augereque significat, cum haec scribit:

Ceterum, dum in vita peregrinantur, apposuit eis iustos, id est, qui propter iustitiam patiuntur persecutiones, beatosque dixit indicans omnia cuique toleranda esse in iustitiam, quandoquidem nos facit, ut tam illi, qui esuriunt iustitiam, refocillentur recreenturque uidendo plerosque iustos, quam ceteri excitentur exhortenturque ad tolerantiam difficultatum atque iniuriarum, quas pati oportet quemque qui paratus est reddere, quae aut Deo aut proximo aut sibi ipsi debentur.

Et paulo infra: "Beati igitur, qui persecutiones patiuntur propter iustitiam, nec dubitare possumus regnum caelorum habitaturos, in cuius possessione iam nunc esse tam multos non dubitamus", martyresne aliosque sanctos in caelis vita aeterna fruentes in mente habens an adhuc in terris commorantes incertum.

Haec fere habui quae ex Callimachi homilia hic depromerem, duplicem illam interpretandi rationem illustrantia, philosophica cum theologicis, rationem cum fide, rerum naturam cum religionis mysteriis, temporalia terrestriaque cum caelestibus aeternisque in uno eodemque discursu coniungentem. Quae ratio, aperte a Callimacho alibi repudiata, si scite recteque est hic a nobis recognita atque descripta, novas certe elicit quaestiones, prima autem omnium est quaestio de tempore, quo Callimachi homilia sit conscripta, nulla enim usquam sive in 
homilia sive in epistula dedicatoria cernuntur indicia, quae quidem ipsa ex se hac de re nos certiores faciant. Sed et haec de tempore et aliae etiam quaestiones, velut sunt de consilio, quo Callimachus materiam tam longe a studiis suis abhorrentem suscepit tractandam, nec non de auctoribus, quos, contemporaneos praesertim vel paucis ante ipsum vigentes, secutus est, alibi, si tempus feret, sunt discutiendae.

\title{
BIBLIOGRAPHIA
}

Atti del Convegno italo-ungherese di studi rinascimentali (Spoleto, 9-10 settembre 1964). "Ungheria d'oggi", 1965, V.

Callimaco Esperiente, poeta e politico del '400. 1987. A cura di G.C. Garfagnini. Firenze: Leo S. Olschki Editore.

L'opera e il pensiero di Giovanni Pico della Mirandola nella storia dell'Umanesimo: convegno internazionale (Mirandola: 15-18 Settembre 1963).

Paparelli Gioacchino. 1977. Callimaco Esperiente (Filippo Buonaccorsi). Seconda edizione. Roma.

Philippi Callimachi, 1967, Epistulae selectee. Edidit et in linguam Polonam vertit Latinas I. Lichońska, Italicas G. Pianko. Commentariis historicis illustravit Th. Kowalewski. Wratislaviae-Varsoviae-Cracoviae: Zakład Narodowy im. Ossolińskich.

Radetti Giorgio. 1963. Il problema del peccato in Giovanni Pico della Mirandola e in Filippo Buonaccorsi. In: L'opera e il pensiero di Giovanni Pico della Mirandola nella storia dell'Umanesimo: convegno internazionale (Mirandola: 15-18 Settembre 1963).

Radetti Giorgio. 1964. L'epicureismo di Gregorio di Sanok, in: Atti del Convegno italoungherese di studi rinascimentali (Spoleto, 9-10 settembre 1964). "Ungheria d'oggi" 1965, V.

Vasoli Cesare. 1987. Il pensiero religioso di Callimaco Esperiente. In: Callimaco Esperiente, poeta e politico del '400. A cura di G.C. Garfagnini, Firenze: Leo S. Olschki Editore.

Juliusz Domański

\section{ABOUT PHILIP KALLIMACH, A HOMILY ABOUT EIGHT BLESSINGS}

\author{
(summary)
}

Filippo Buonaccorsi, called "Callimachus", in his homily on the Beatitudes, pairs the eight blessings, without observing the order in which they appear in the Gospels. Sometimes he contrasts them gently with each other, but sometimes the principle of pairing them 
remains unclear. The author of this contributory article draws the reader's attention to this binary arrangement of the Beatitudes hoping that, in this way, Buonaccorsi's source of inspiration can be found, which he cannot provide himself.

\section{KEYWORDS}

Filippo Buonaccorsi called "Callimachus" as a homiletic writer, the Beatitudes, the binary arrangement of the Beatitudes in Buonaccorsi's homily 
